Research Article

\title{
Effect of Traverse Speed on the Defect Characteristic, Microstructure, and Mechanical Property of Friction Stir Welded T-Joints of Dissimilar Mg/Al Alloy
}

\author{
Sun Tao, Wu Siyu, Yifu Shen $\mathbb{D}^{D}$, Jin Jiayi, Lu Jiazhu, and Qin Tianxiang \\ College of Materials Science and Technology, Nanjing University of Aeronautics and Astronautics, 29 Jiangjun Road, \\ Nanjing 210016, China \\ Correspondence should be addressed to Yifu Shen; yfshen_nuaa@hotmail.com
}

Received 4 August 2020; Revised 29 October 2020; Accepted 9 November 2020; Published 21 November 2020

Academic Editor: Michelina Catauro

Copyright $(2020$ Sun Tao et al. This is an open access article distributed under the Creative Commons Attribution License, which permits unrestricted use, distribution, and reproduction in any medium, provided the original work is properly cited.

The AZ31 B/2024-T4 T-lap-joint was successfully fabricated by friction stir welding (FSW) with different welding parameters. The defect characteristics and metallurgical structure were observed and analyzed using optical microscope (OM) and scanning electron microscopy (SEM). Besides, the effects of defects and welding parameters on mechanical properties were investigated. The results show that an effective metallurgical reaction zone can be formed between $\mathrm{Mg}$ and $\mathrm{Al}(\mathrm{Mg}-\mathrm{Al} \mathrm{MRZ)}$ and the island structures and lamellar structures appeared in the Mg-Al MRZ. The T-joints without tunnel defects can be obtained and the excellent mechanical properties of the T-joint were achieved using the welding speed of $50 \mathrm{~mm} / \mathrm{min}$. The tensile strength along the skin and the stringer was mainly affected by the kiss bonding defects.

\section{Introduction}

Aluminum and magnesium alloys, as two ideal materials for light weighting, are widely used in aerospace, automobile manufacturing, and other fields [1]. However, magnesium alloys have poor corrosion resistance and high brittleness, so $\mathrm{Al} / \mathrm{Mg}$ dissimilar alloy welding is a hot research topic in order to improve the utilization of magnesium in recent years [2-4]. The characteristics of low melting point and easy oxidation of $\mathrm{Al}$ and $\mathrm{Mg}$ lead to poor welding performance. On the other hand, T-joints are widely used in the connection of aircraft skins and stringers and automobile structural parts, which can bear unidirectional stress and multiple sets of combined stress $[5,6]$. The current T-joints are mainly obtained by fusion welding and riveting $[7,8]$. If fusion welding is used to weld $\mathrm{Al}$ and $\mathrm{Mg}$ alloys, it will inevitably lead to poor welding quality. At the same time, riveting will significantly increase the weight. Friction stir welding (FSW), as a solid phase welding process, perfectly solves these problems. FSW has irreplaceable advantages in the welding of $\mathrm{Al} / \mathrm{Mg}$ alloys [9]. In these conditions, the research on $\mathrm{Mg} / \mathrm{Al}$ dissimilar metal $\mathrm{T}$-joints has great practical significance.

Predecessors have done a lot of research on $\mathrm{Al} / \mathrm{Mg}$ FSW and T-joint. Sameer et al. [10] prepared AZ91 and AA6082T6 butt joints and found that the mechanical properties of the joints obtained were better when $\mathrm{Mg}$ was placed on the forward side (AS). Lakshmana [11] and others obtained the butt joint of AZ91 magnesium alloy and Al6063 aluminum alloy by FSW and found that the joint was formed mainly due to the mechanical mixing of materials. Meng et al. [12] found that the aid of ultrasound can solve the problem of the adhesion of the rotation tool and significantly promote the complete mixing of the materials in the nugget zone (NZ). Mohammadi et al. [13] fabricated lapped FSW joints between different AZ31B and 6061 and found that the strength of the joint mainly depended on the distribution characteristics of intermetallic compounds (IMCs). Ji et al. [14] successfully completed the friction stir lap welding of $\mathrm{Al} / \mathrm{Mg}$ alloys by adding $\mathrm{Zn}$ foil, which improved the distribution of IMCs and increased the strength. Cui et al. $[15,16]$ used three combinations of skins and stringers to obtain AA6061 
FSW T-joints. They revealed the defect characteristics of $\mathrm{T}$-joints and analyzed the influence of defects on tensile strength and the best assembly method was given finally. Feistauer [17] and his colleagues used a second pass to ensure the welding of the $\mathrm{Al} / \mathrm{Mg} \mathrm{T}$-joint by maintaining a similar speed, which significantly reduced the kissing defect on the retreating side (RS). Fratini [18] studied the effects of material properties on $\mathrm{T}$-joints and found that the materialrelated thermal and plastic fields affect the thermomechanical affected zone (TMAZ), heat-affected zone (HAZ), and nugget zone in the joint. Buffa [19] focused on the problem of material flow in T-joint FSW through experiments and numerical analysis. The results show that vertical logistics has a greater impact on the mechanical properties of the joint.

So far, researches on $\mathrm{Al} / \mathrm{Mg}$ dissimilar metals FSW are limited to butt joints and lap joints, and there are a few researches on $\mathrm{T}$-joints. At the same time, research on $\mathrm{T}$-joints is mostly limited to the same and dissimilar aluminum alloy. The research on the T-joint of aluminum alloy and magnesium alloy has not been involved. In this paper, improvements and innovations have been made on the basis of existing research. The FSW of $\mathrm{Mg} / \mathrm{Al} \mathrm{T}$-joint was completed with a special fixture. The structure, defects, and mechanical properties will be analyzed, which will open up a new path for dissimilar welding.

\section{Experimental Procedures}

In this experiment, the AZ31 B magnesium alloy with a size of $3 \times 180 \times 100 \mathrm{~mm}$ was used as skin and the stringer was the 2024 -T4 aluminum alloy with a size of $4 \times 180 \times 60 \mathrm{~mm}$. The chemical composition and mechanical properties at room temperature of the base material (BM) are shown in Tables 1-3, separately. Before welding, the surfaces were polished by abrasive paper and cleaned with acetone to remove the surface oxide film and oil stain.

During the welding, the special fixture for $\mathrm{T}$-joint was simplified and manufactured, which referred to the T-joint fixture designed by Fratini [19]. Figure 1 is a schematic diagram of T-joint welding. The upper two back plates are used to fix the skin, and the lower two back plates fix the stringers. Different from the former, the latter is a back plate with arc transition angle. The two rounded corners can avoid collision between the fixture and the pin and prevent the plasticized metal from dripping, which can ensure that the corners of the T-joint have a good formability. In the experiment, the welding tool is made of $\mathrm{H} 13$ steel, including a concave shoulder and a threaded tapered tool pin, as shown in Figures 2(a) and 2(b) that show the actual picture of the welding process. After a series of preliminary experiments, the constant rotation speed $(1000 \mathrm{r} / \mathrm{min})$, constant plunge depth $(0.3 \mathrm{~mm})$, constant fillet radius $(r=2 \mathrm{~mm})$, and traverse speed of $15-80 \mathrm{~mm} / \mathrm{min}$ were employed. In addition, the rotating tool was tilted back $1.8^{\circ}$ during welding.

After welding, the obtained $\mathrm{T}$-joint welding was analyzed in cross section perpendicular to the welding direction. The sample was ground and polished. Finally, the mirror surface was etched with $4 \%$ nitric acid alcohol solution for
TABLE 1: Main chemical composition of AZ31 B magnesium alloy (mass fraction,\%).

\begin{tabular}{lcccccccc}
\hline $\mathrm{Al}$ & $\mathrm{Zn}$ & $\mathrm{Mn}$ & $\mathrm{Si}$ & $\mathrm{Cu}$ & $\mathrm{Ni}$ & $\mathrm{Fe}$ & $\mathrm{Ca}$ & $\mathrm{Mg}$ \\
\hline $2.5 \sim 3.5$ & $0.6 \sim 1.4$ & $0.2 \sim 1.0$ & 0.08 & 0.01 & 0.001 & 0.003 & 0.04 & Bal. \\
\hline
\end{tabular}

TABLE 2: Main chemical composition of 2024-T4 aluminum alloy (mass fraction,\%).

\begin{tabular}{ccccccccc}
\hline $\mathrm{Cu}$ & $\mathrm{Mg}$ & $\mathrm{Mn}$ & $\mathrm{Si}$ & $\mathrm{Fe}$ & $\mathrm{Zn}$ & $\mathrm{Ti}$ & $\mathrm{Ni}$ & $\mathrm{Al}$ \\
\hline 3.8 & 1.5 & 0.6 & 0.5 & 0.5 & 0.3 & 0.15 & 0.1 & $\mathrm{Bal}$. \\
\hline
\end{tabular}

TABLE 3: Mechanical properties of base metal.

\begin{tabular}{lcc}
\hline $\begin{array}{l}\text { Base } \\
\text { materials }\end{array}$ & $\begin{array}{c}\text { Ultimate tensile strength } \\
(\mathrm{MPa})\end{array}$ & $\begin{array}{c}\text { Microhardness } \\
(\mathrm{HV})\end{array}$ \\
\hline AZ31B & 194 & 70 \\
$2024-\mathrm{T} 4$ & 470 & 100 \\
\hline
\end{tabular}

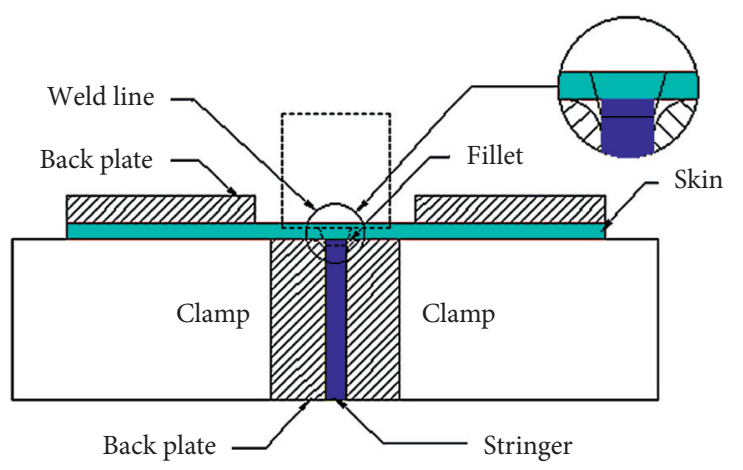

FIgURE 1: Schematic diagram of the friction stir welding process of T-joint.

about 45 seconds, and the cross section of sample was observed with the OLYMPUS GX51 optical microscope (OM). SEM (Hitachi S-4800 field emission scanning electron microscope) was used to observe finer microstructure, and energy spectrometer (EDS: Bruker's Quantax-400) was used to detect chemical compositions. The microhardness of the cross section of the joints was measured in the horizontal and vertical directions employing an HXS-1000 microhardness tester. A load of $0.98 \mathrm{~N}$ for $15 \mathrm{~s}$ dwell time and an interval of $0.5 \mathrm{~mm}$ were adopted. The tensile properties were tested via a CMT 5105 SANS tensile machine at room temperature. Under each welding condition, six specimens were prepared for tensile test. Three of them are used for the tensile test along the skin (as shown in Figure 3), and the other three are used for the tensile test along the stringer (as shown in Figure 4). Due to the particularity of the stringer structure, a special drawing fixture was designed for cross drawing. Figure 5 shows the tensile process. Three tensile specimens cut from the same joint were used to evaluate the results of each joint. The fracture characteristics of the joints were observed with an SEM. 

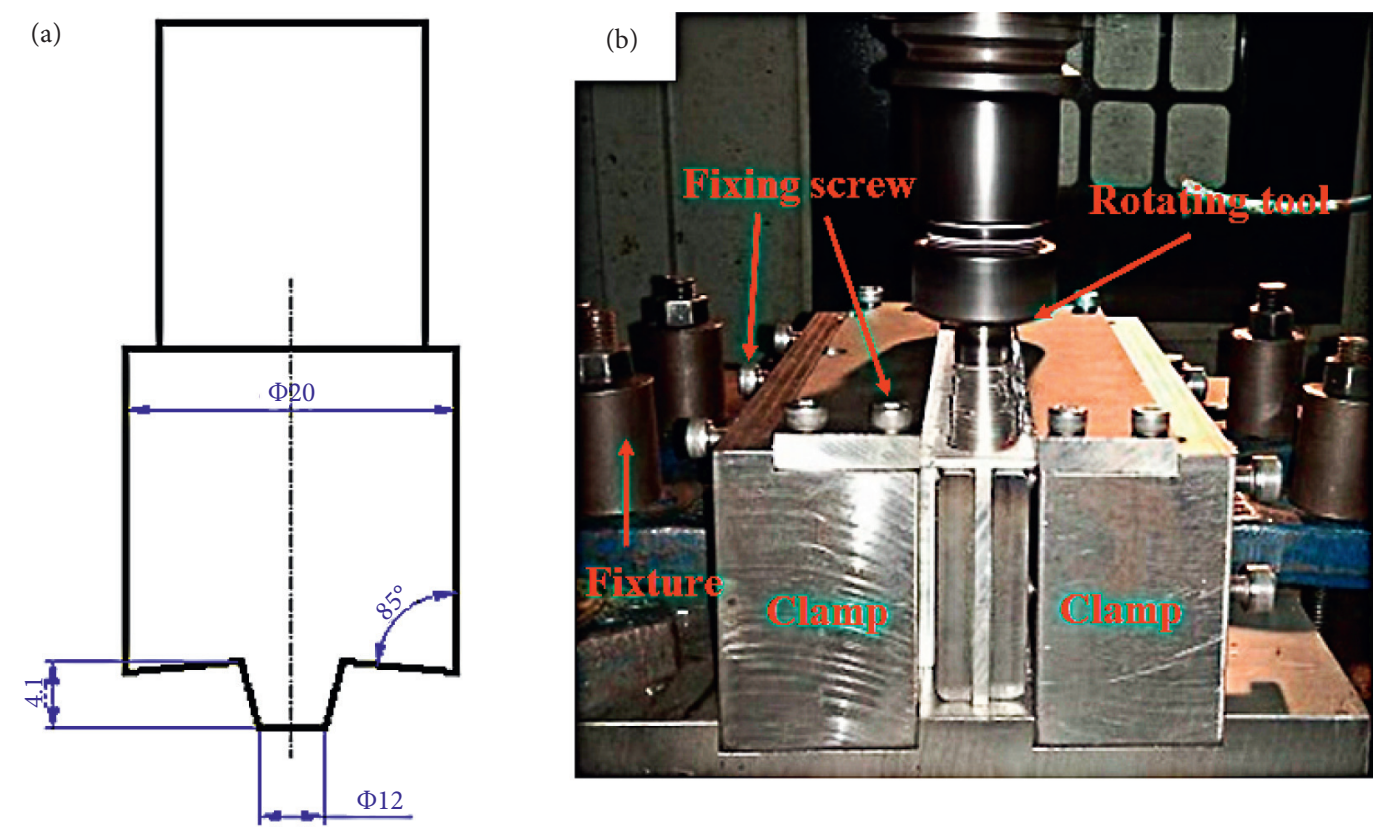

Figure 2: (a) Schematic drawing of the welding tool (in $\mathrm{mm}$ ). (b) Actual picture of welding process.

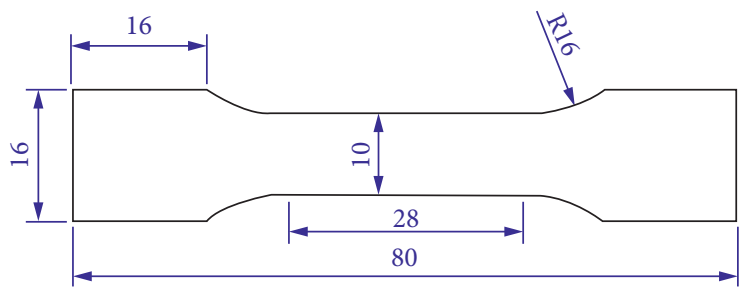

Figure 3: Dimensions of tensile samples along the skin (in $\mathrm{mm}$ ).
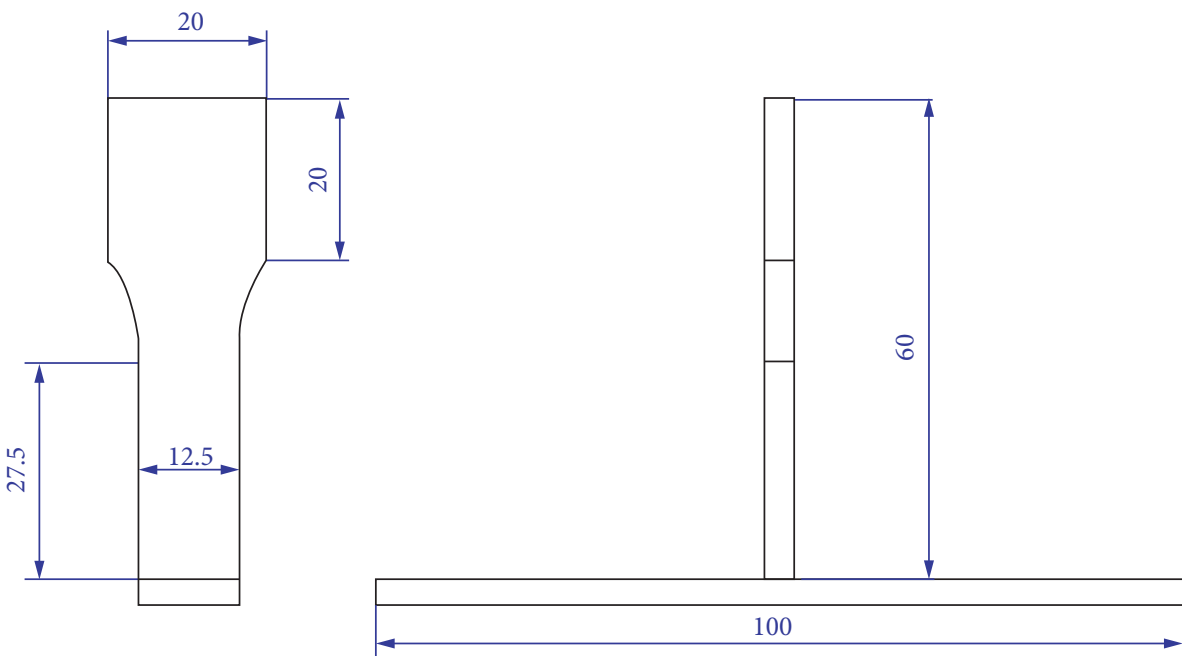

FIGURE 4: Dimensions of tensile samples along the stringer (in $\mathrm{mm}$ ).

\section{Results and Discussion}

3.1. Macroscopic Morphology Observation. Figure 6 shows the overall appearance of a welded T-joint. The fillet weld is fully filled. Two corner curvatures helped to reduce stress concentration on the corners of the weldment.
Surface defects usually lead to internal defects in the weld, so the surface quality can be used as a criterion for evaluating the quality of the weld. Figure 7 shows the surface morphology of each group of patterns. It can be found that flashes, holes, peeling, and other defects will appear on the surface of the weld at higher or lower welding speeds. The 

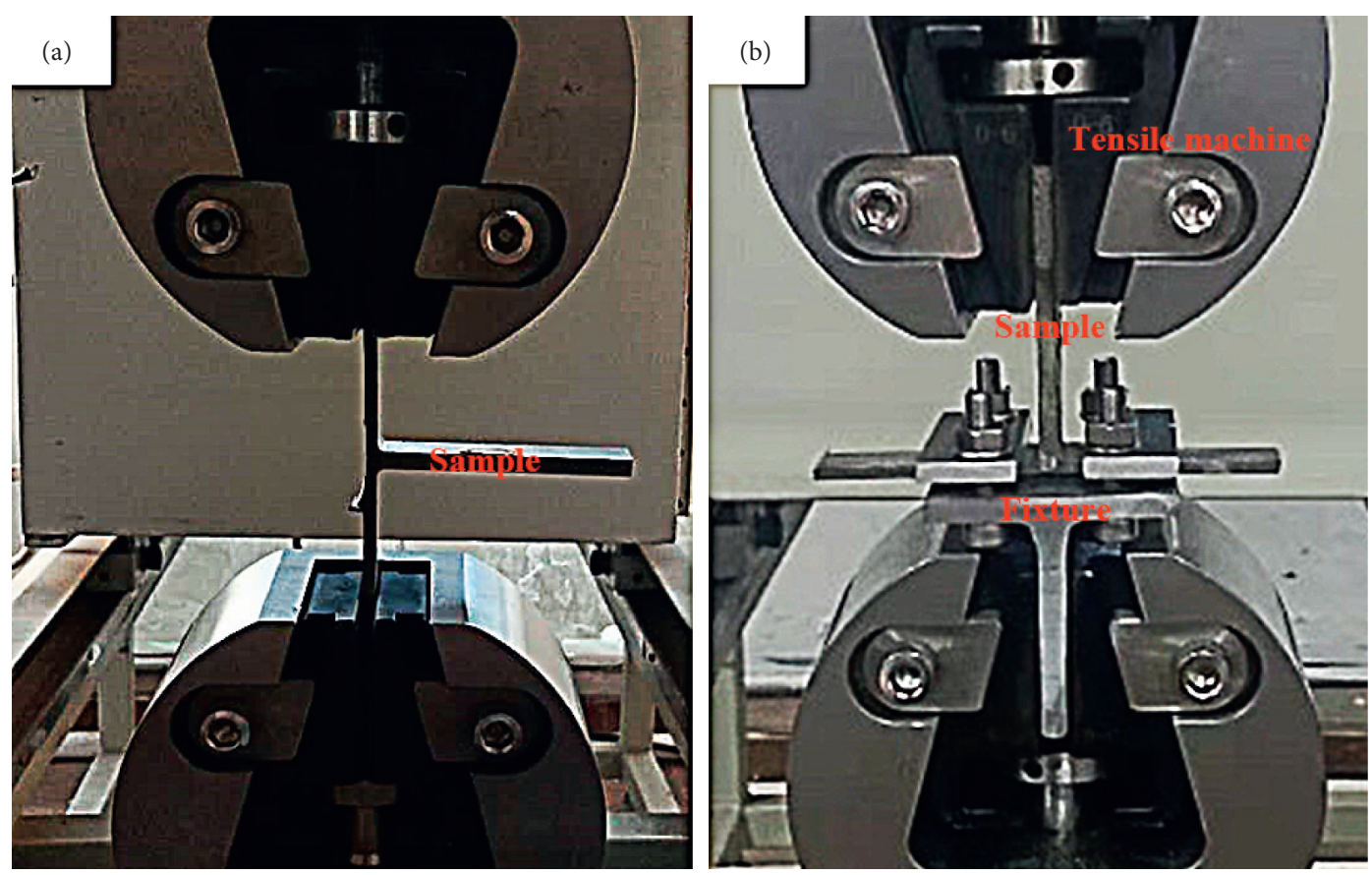

Figure 5: Real pictures of tensile test. (a) Along the skin and (b) along the stringer.

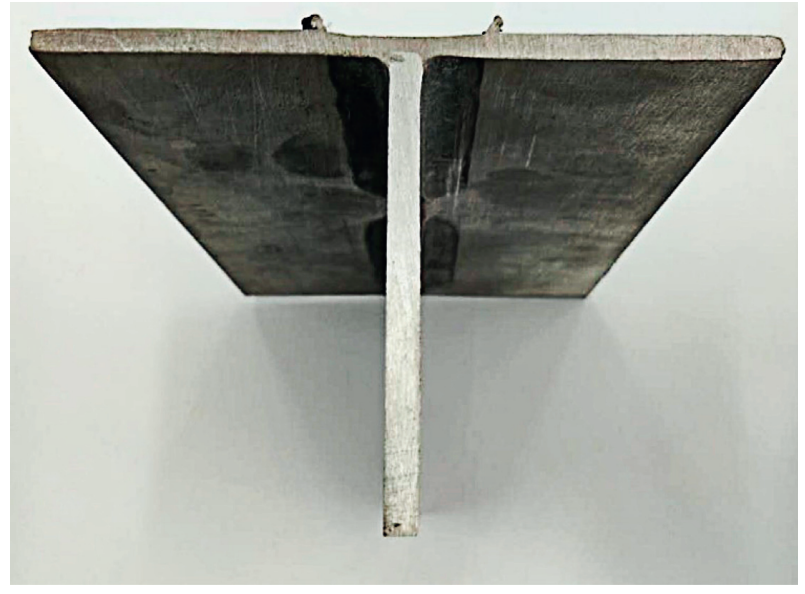

FIGURE 6: Overall appearance of a welded T-joint.

reason may be that the rotate tool on the unit length weld had a long stay time when the welding speed was very small and the heat input is too large, which led to too serious metal plasticization. Under the effect of the forging pressure and the rotational friction of the shoulder, the material was squeezed onto the surface of the weld. The movement of the rotate tool was not a continuous movement, but a linear motion with a slight pause [20]; thereby, semicircle lines were formed on the surface. When the welding speed exceeded a certain value, the rotating stirring effect was relatively weak due to insufficient heat input, which resulted in poor surface.

Figure 8 shows the cross sections of T-joints obtained at different welding speeds. For all joints, a magnesiumaluminum mixed reaction area ( $\mathrm{Mg}-\mathrm{Al} \mathrm{MRZ})$ with a certain thickness can be seen between the skin and the stringer.
From the Mg-Al MRZ, the vertical flow characteristics, which the materials flow to the advancing side, can be seen. As the welding speed increases, the metal flow range shrinks, and the area of Mg-Al MRZ decreases. The main reason is that the residence time of the rotate tool per unit length is short with the increase of the welding speed, so the rotation stirring effect is reduced. As we know, the heat input decreases with an increase in welding speed [21]. As a result, the lower peak temperature of the weld could be developed which limited the atomic diffusion ability, reducing the metallurgical reaction to some extent.

3.2. Defect Characteristics. Tunnel defects, cold lap, hook, and kiss bonding are the most typical defects in the process of FSW T-joints. Figure 8 shows that too small or too large welding speed is easy to form the tunnel defect. The lower traverse speed was conducive to generate enough heat and more plastic metal. Therefore, a larger amount of the plasticized materials was extruded out of the stir zone with the improvement of the flowability, so tunnel defects occurred at $15 \mathrm{~mm} / \mathrm{min}$. But too higher traverse speed will result in short residence time of the rotate tool, so the heat input was insufficient. The flowability of the material decreases, and the metal on the backward side cannot fill the microscopic cavity left by the forward side, thus forming tunnel defects.

During the welding process, after the $\mathrm{Mg} / \mathrm{Al}$ interface is penetrated by the pin, the tapered pin will cause the original overlapping interface to bend upward along the tapered surface. At the same time, the material in the NZ would flow down and accumulate near the pin tip. The accumulated material would force the material in the TMAZ to flow upward and further push the original lap interface to bend 

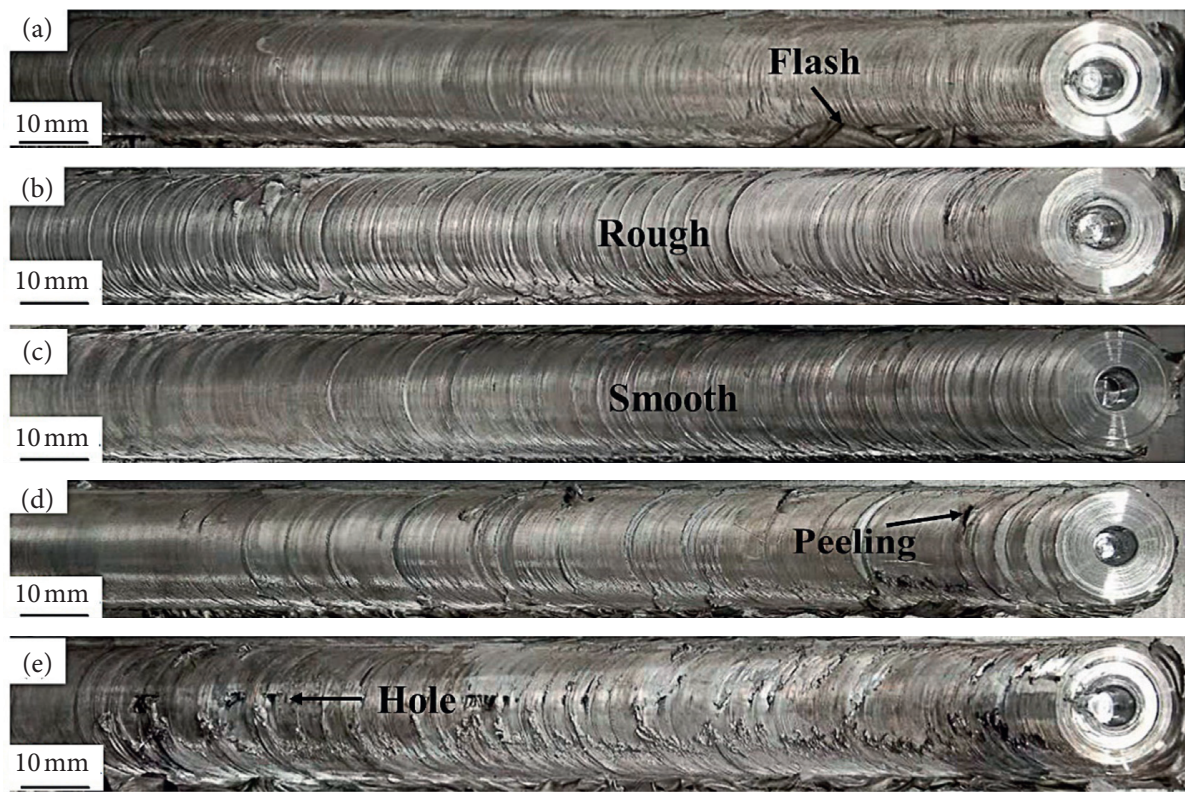

Figure 7: Macroscopic appearance of each sample under different welding parameters: (a) $15 \mathrm{~mm} / \mathrm{min}$; (b) $30 \mathrm{~mm} / \mathrm{min}$; (c) $50 \mathrm{~mm} / \mathrm{min}$; (d) $65 \mathrm{~mm} / \mathrm{min}$; (e) $80 \mathrm{~mm} / \mathrm{min}$.

upward. Thus, hook and cold lap were formed at the AS and RS, respectively, as shown in Figure 9. The height and width of cold lap and hook defects decrease as the welding speed increases. When the welding speed increases from 15 to $80 \mathrm{~mm} / \mathrm{min}$, the geometric heights of hook defects are $1.53 \mathrm{~mm}, 1.38 \mathrm{~mm}, 1.25 \mathrm{~mm}$, and $0.48 \mathrm{~mm}$, respectively. At the same time, the geometric width of the hook has a similar change rule, as shown in Figure 9.

In addition, the hook and cold lap limit the heat input and mechanical flow of the fillet weld metal while the aluminum-magnesium bond requires the interdiffusion of elements to form a metallurgical bond, so there is not enough driving force to undergo a solid phase transition to form a metallurgical bond area. Therefore, the kiss bonding defects appear in the fillet weld (see Figure 10). In order to explore the chemical composition of the kiss bonding defect, the EDS analysis results are shown in Figure 10. The oxygen content on the AS and the RS reached $6.62 \%$ and $5.21 \%$, respectively. This may be because the cleaning process is not perfect, and there will always be oxide residues on the metal surface. At the same time, due to the high temperature of the weld during the welding process, aluminum and magnesium were easily oxidized to form an oxide film.

3.3. Metallurgical Structure Analysis. According to the aluminum-magnesium phase diagram, two eutectic reactions can occur during the welding process: $L \longrightarrow{ }^{7} 10.15 \mathrm{~K} \mathrm{Al} l_{12} \mathrm{Mg}_{17}+\beta$ and $L \longrightarrow^{7} 23.15 \mathrm{~K} \mathrm{Al}_{3} \mathrm{Mg}_{2}+$ $\alpha$ [22], which is a prerequisite for aluminum-magnesium welding.

Figure 11 shows the morphology of the cold lap and hook at the traverse of $15 \mathrm{~mm} / \mathrm{min}$. The results of the surface scan and point scan show that the internal interface is well connected with the eutectic structure (ES) and the outer sides also formed a metallurgical connection, which shows that the cold lap and hook defects increase the bonding area. It is beneficial to improve the strength.

Figures $12-15$ show the typical microstructure at different traverse speeds. Some typical structures appear in $\mathrm{Mg} / \mathrm{Al} \mathrm{T}$-joints. Figures 12(a) and 12(b) show the OM image of island structure (IS) and lamellar structure (LS), respectively. Figure 12(c) indicates that the fine equiaxed grains were formed in the NZ, which suggests that the plasticized metal had undergone sufficient dynamic recrystallization. The IS and LS appear in the NZ and TMAZ near AS. The grains in the NZ and the EDS (Figure 13) element analysis of the IS show that the lighter layer contained about $59.03 \% \mathrm{Mg}$, which suggests that the phase was most likely Al12Mg17. The dark gray layer which was likely related to the $\mathrm{Mg}$ phase due to its higher $\mathrm{Mg}$ content was much more susceptible to corrosion and was preferentially etched out as dark pits. The $\mathrm{Mg}$ - $\mathrm{Al}$ phase diagram [22] suggests that the observed microstructures consist of mainly Al12Mg17 intermetallic phases, which occur in this binary system. The Mg matrix is dispersed in the eutectic structure. Based on Figure 14, the Al12Mg17 intermetallic phases with irregular shape were observed in the LS of the skin, indicating that the welding process resulted from the vertical displacement of material from the bottom $\mathrm{Al}$ alloy sheet, which led to the formation of LS. Furthermore, the net-like eutectic structure (ES) was formed in NZ as shown in Figure 15. This may be due to the higher heat input generated at a speed of $1000 \mathrm{r} / \mathrm{min}$ so that the metal in the $\mathrm{Mg}-\mathrm{Al}$ bond zone melts. Obviously, the net-like ES grains are very coarse at $15 \mathrm{~mm} / \mathrm{min}$. The grains are getting finer and finer as the welding speed increases because of the reduction of peak temperature in NZ. When the welding speed reaches $65 \mathrm{~mm} / \mathrm{min}$, the IMCs are already distributed on the substrate in dots. 

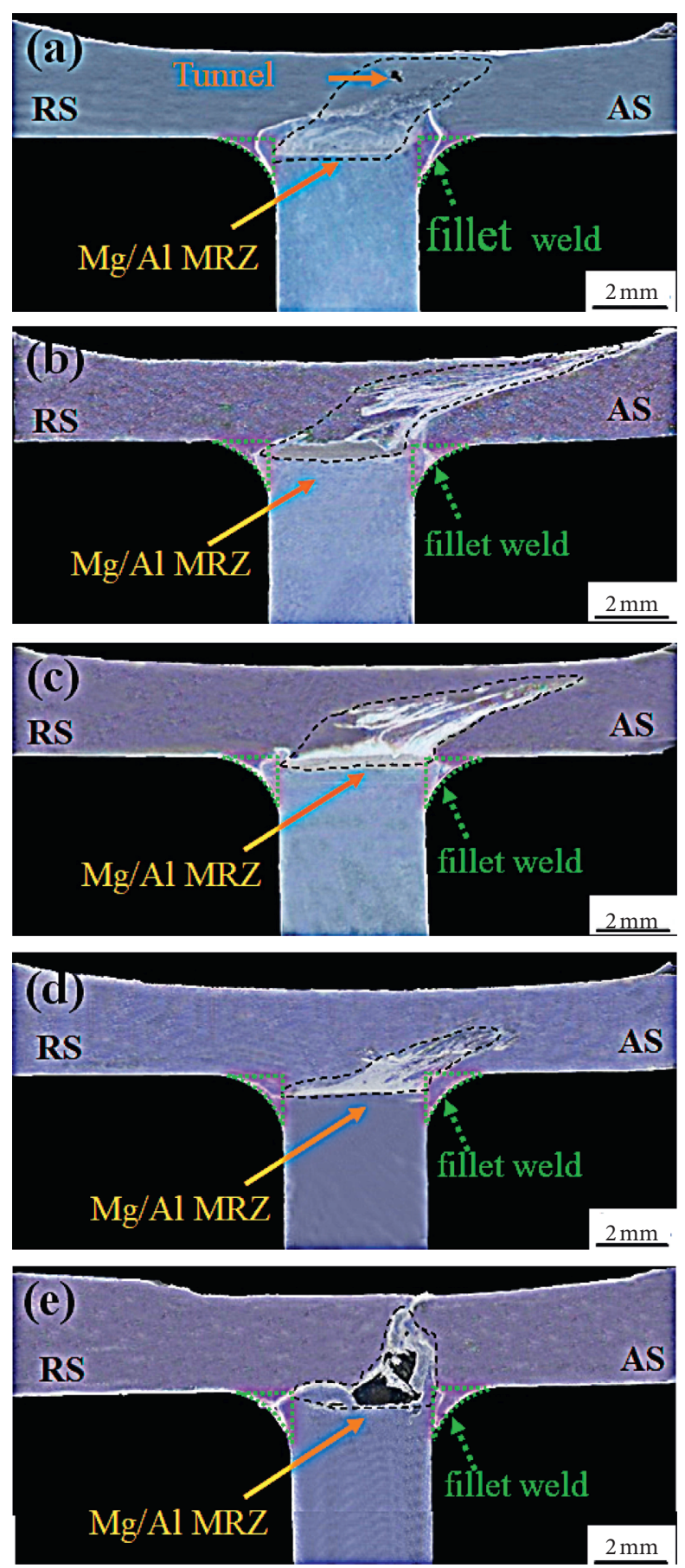

Figure 8: Cross section of T-joint: (a) $15 \mathrm{~mm} / \mathrm{min}$; (b) $30 \mathrm{~mm} / \mathrm{min}$; (c) $50 \mathrm{~mm} / \mathrm{min}$; (d) $65 \mathrm{~mm} / \mathrm{min}$; (e) $80 \mathrm{~mm} / \mathrm{min}$.

3.4. Mechanical Property. On the cross section perpendicular to the welding direction, samples of all parameters were tested for microhardness profile in the skin and stringer directions, as shown in Figures 16 and 17, respectively. The tensile strength of all styles of T-joints is shown in Figure 18.

From Figure 16, we can see that all samples have similar hardness distribution characteristics along the skin, and the hardness is a typical "W" type. In the range of about 0-10 $\mathrm{mm}$ from the weld center, the microhardness presents a decreasing trend and reaches $48 \mathrm{HV}$ at $30 \mathrm{~mm} / \mathrm{min}$. In the range of about 10-20 $\mathrm{mm}$ from the weld, it can be found that the hardness increases rapidly to the values of PM. The hardness value of NZ is the highest and even exceeds the hardness of the PM. This phenomenon may be caused by solution strengthening and fine grain strengthening [23].

The lowest hardness value appears in the heat-affected zone (HAZ), which is about $10 \mathrm{~mm}$ from the center of the weld. The HAZ was far away from the weld and only subjected to thermal cycling, so the grains grew rapidly and the dispersed fine strengthening phase in the 

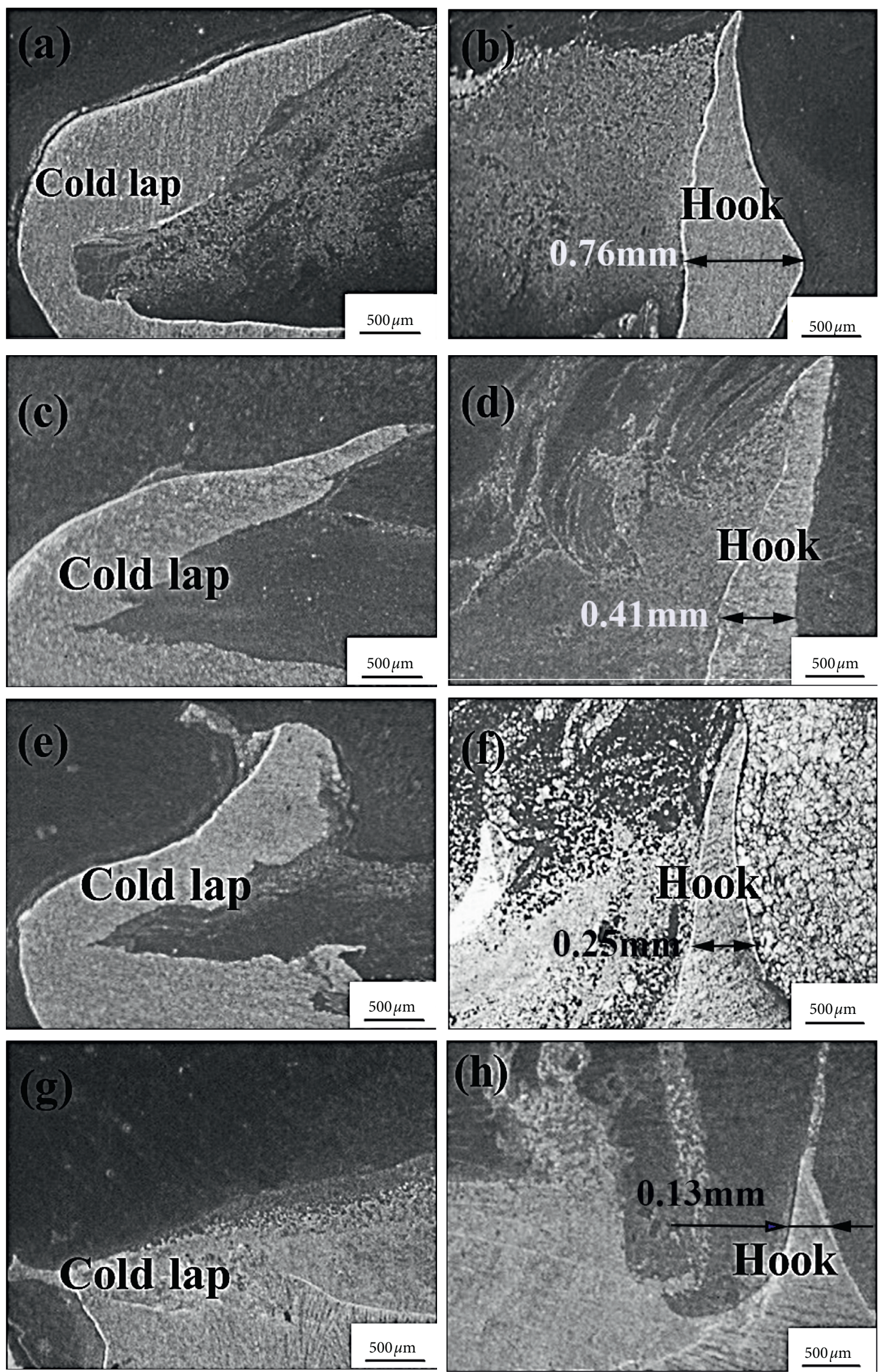

FIGURE 9: Morphology of cold lap and hook defects at different traverse speeds: (a) and (b) $15 \mathrm{~mm} / \mathrm{min}$; (c) and (d) $30 \mathrm{~mm} / \mathrm{min}$; (e) and (f) $50 \mathrm{~mm} / \mathrm{min}$; (g) and (h) $65 \mathrm{~mm} / \mathrm{min}$. 

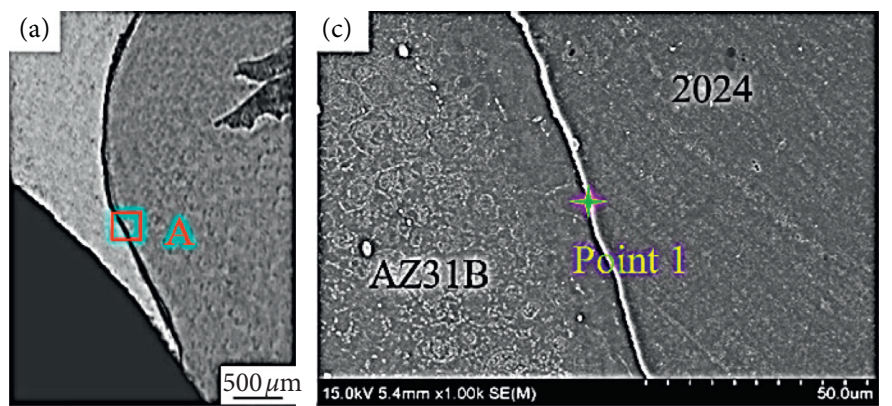

(e)
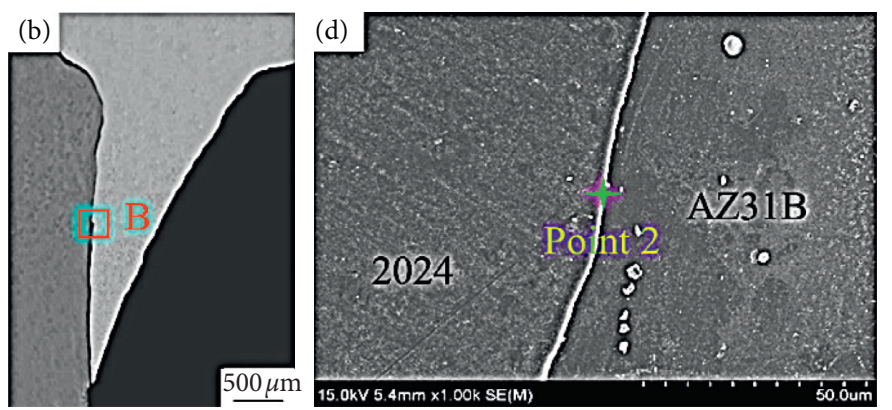

\begin{tabular}{ccc}
\hline Element & Weight & Atomic \\
\hline $\mathrm{Mg}$ & 8.02 & 8.45 \\
$\mathrm{Al}$ & 88.69 & 86.34 \\
$\mathrm{O}$ & 3.29 & 5.21 \\
Total & 100 & 100 \\
\hline
\end{tabular}

\begin{tabular}{|c|c|c|}
\hline Element & Weight & Atomic \\
\hline $\mathrm{Mg}$ & 86.42 & 85.11 \\
\hline $\mathrm{Al}$ & 9.10 & 8.27 \\
\hline $\mathrm{O}$ & 4.48 & 6.62 \\
\hline Total & 100 & 100 \\
\hline
\end{tabular}

FIGURE 10: The macroscopic appearance of the kissing bond defect of (a) RS and (b) AS of sample WS30. The enlarged SEM views of A region (c) and B region (d). The EDS result of point 1 (e) and point 2 (f) of the kiss bonding defects.

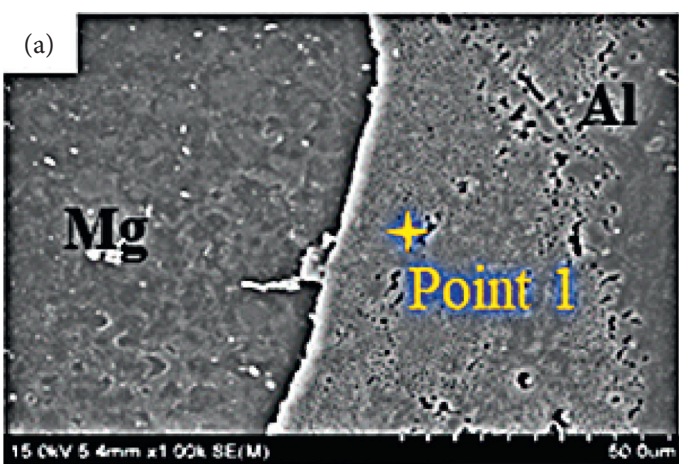

\begin{tabular}{ccc}
\hline Element & Weight & Atomic \\
\hline $\mathrm{Mg}$ & 56.06 & 58.02 \\
$\mathrm{Al}$ & 43.94 & 41.98 \\
Total & 100 & 100 \\
\hline & $\mathrm{Al}_{12} \mathrm{Mg}_{17}+(\mathrm{Mg})$ & \\
\hline
\end{tabular}

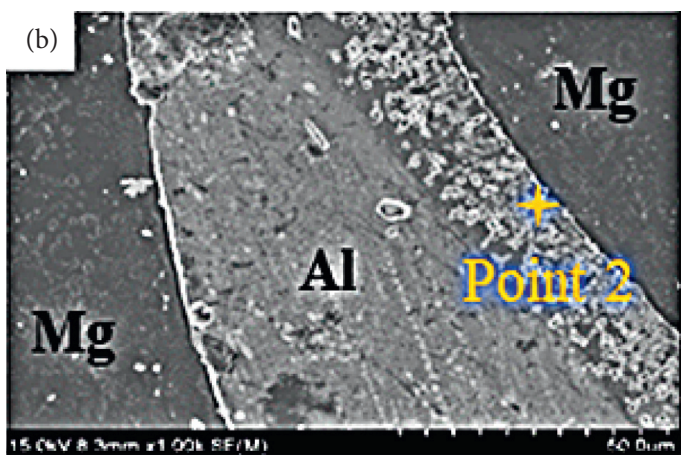

\begin{tabular}{ccc}
\hline Element & Weight & Atomic \\
\hline $\mathrm{Mg}$ & 58.64 & 61.15 \\
$\mathrm{Al}$ & 41.36 & 38.85 \\
Total & 100 & 100 \\
\hline & $\mathrm{Al}_{12} \mathrm{Mg}_{17}+(\mathrm{Mg})$ &
\end{tabular}

FIGURE 11: SEM and EDS results of cold lap and hook: (a) enlarged view of the cold lap and (b) enlarged view of the hook.

magnesium alloy matrix segregated to be overaging, which made the hardness value relatively low. In general, the hardness profile trend is basically symmetrical along both sides of the weld center. In the TMAZ and the HAZ next to the TMAZ, the hardness at the RS is higher than that at the AS. The reason is that the AS is subjected to the thermal 

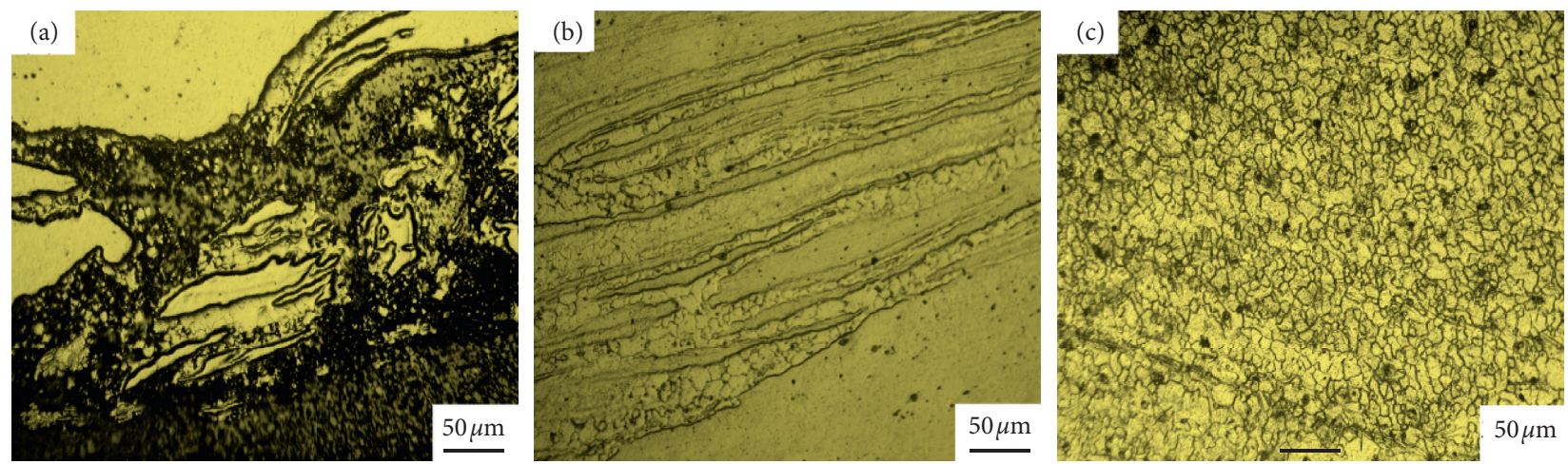

FIgURE 12: Typical images (OM) of microstructure: (a) the IS with $30 \mathrm{~mm} / \mathrm{min}$; (b) the LS with $50 \mathrm{~mm} / \mathrm{min}$; (c) the ES with $65 \mathrm{~mm} / \mathrm{min}$.
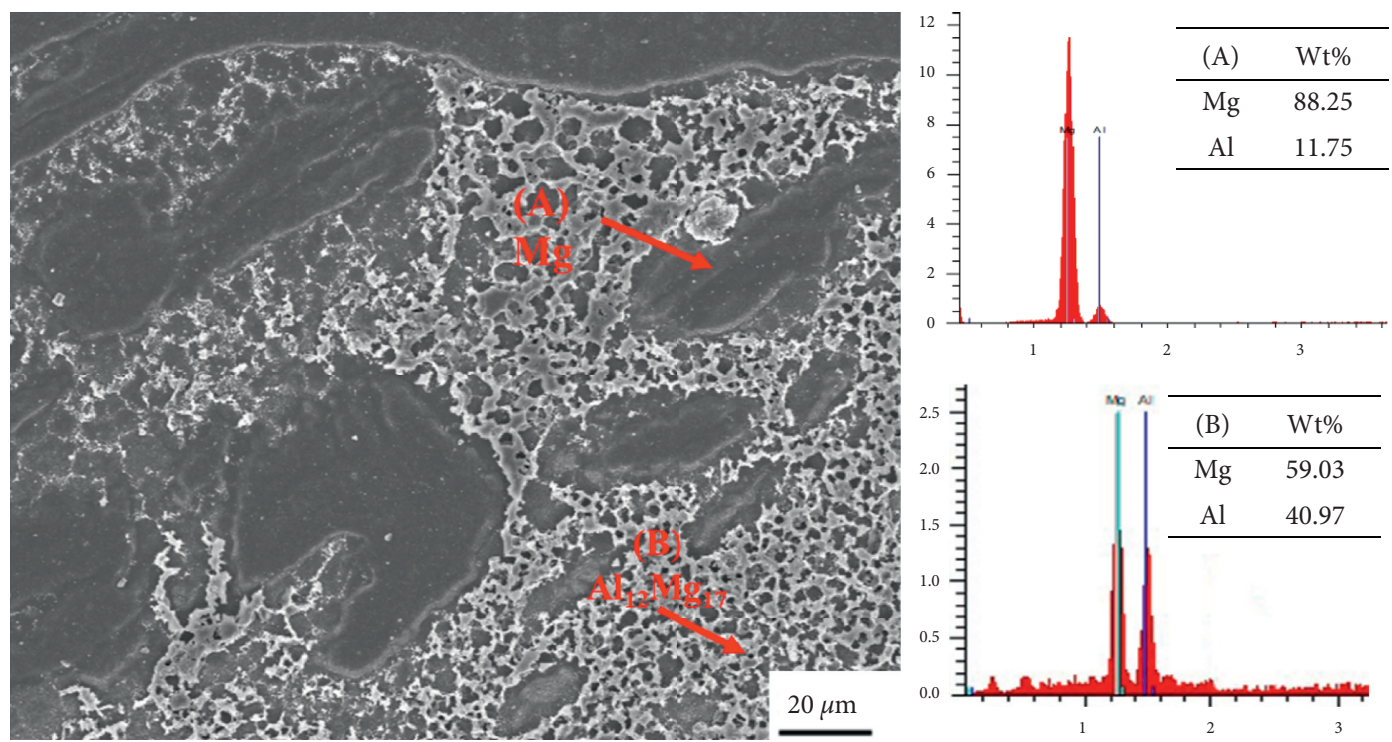

Figure 13: SEM view and the EDS element analysis of the IS.
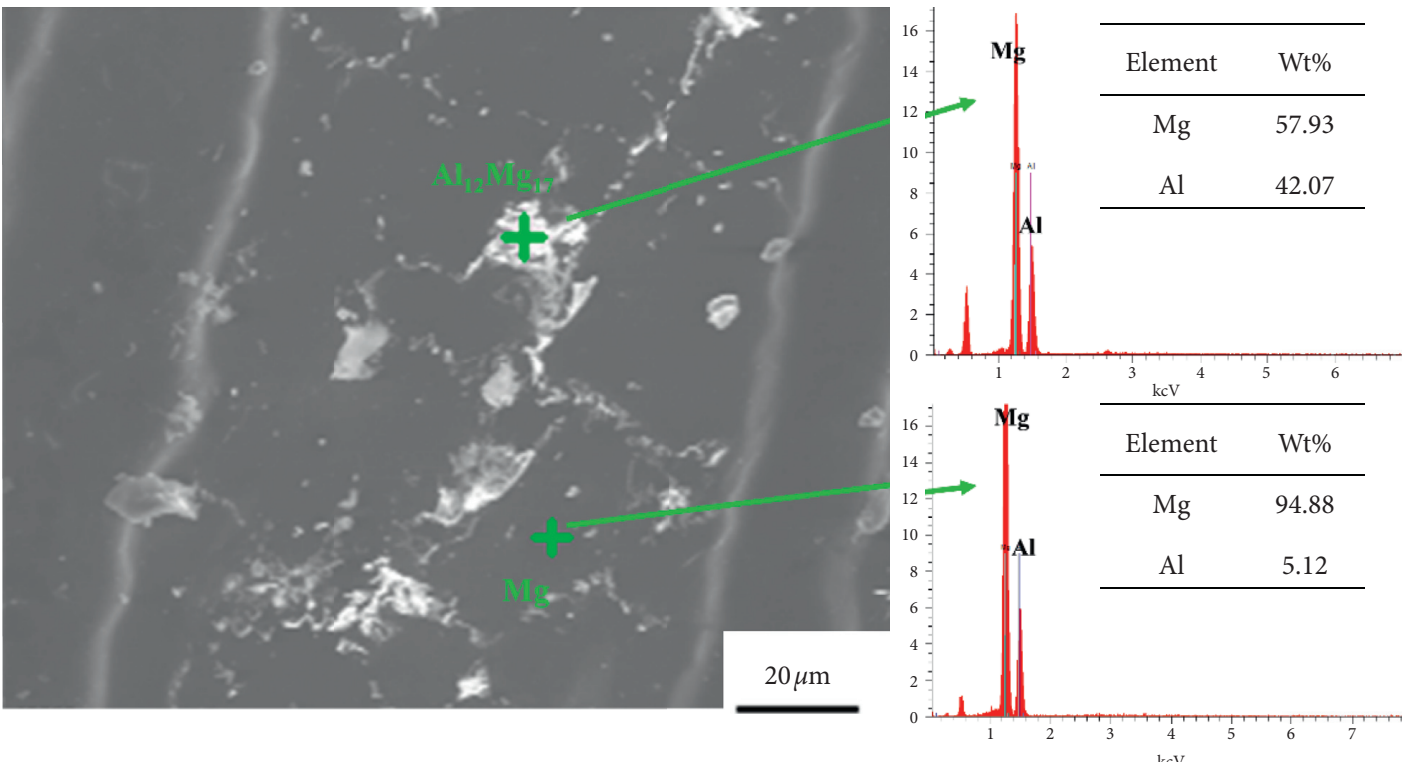

FIGURE 14: SEM view and the EDS element analysis of the LS. 

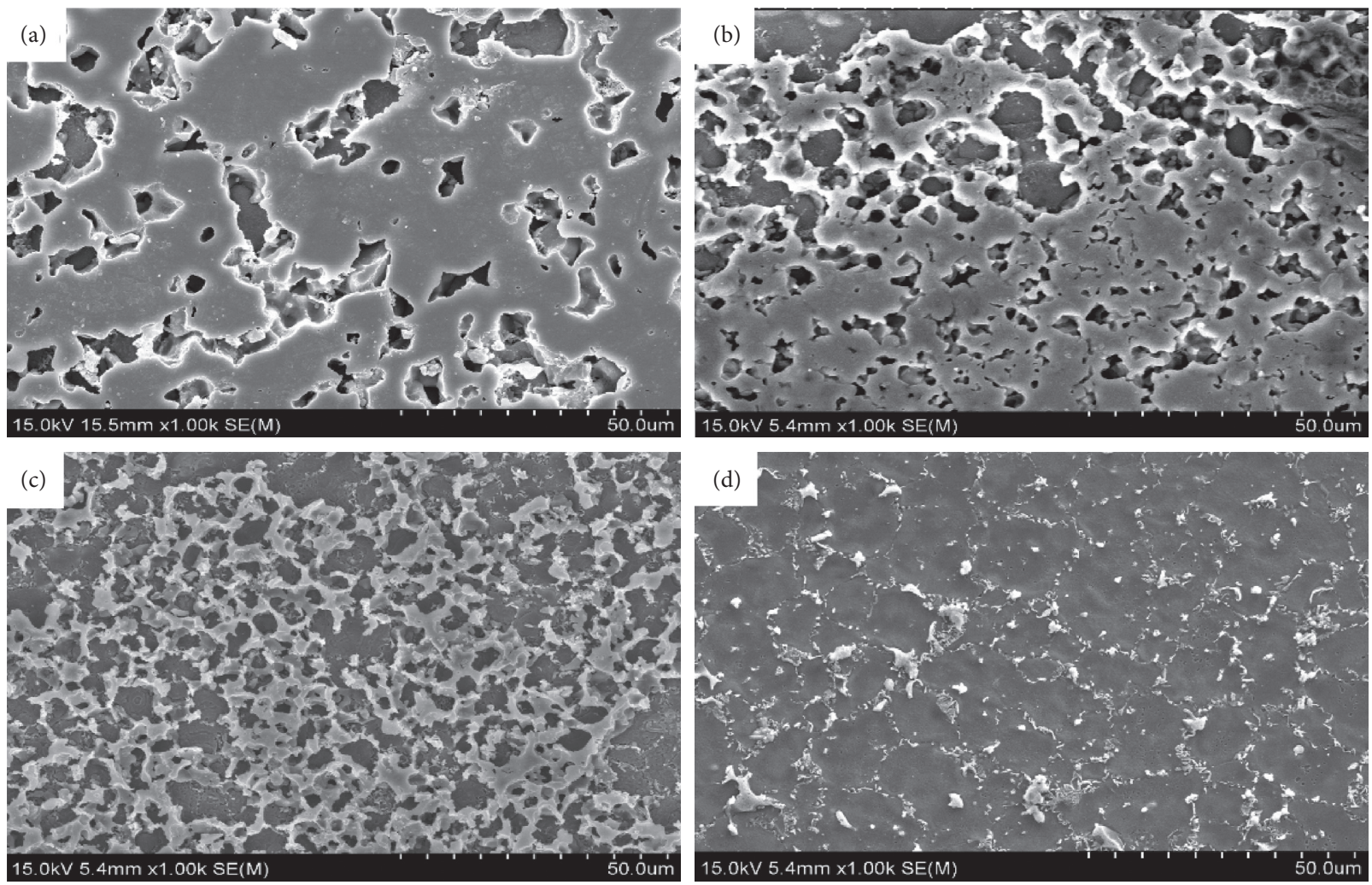

Figure 15: SEM view and element analysis of the ES.

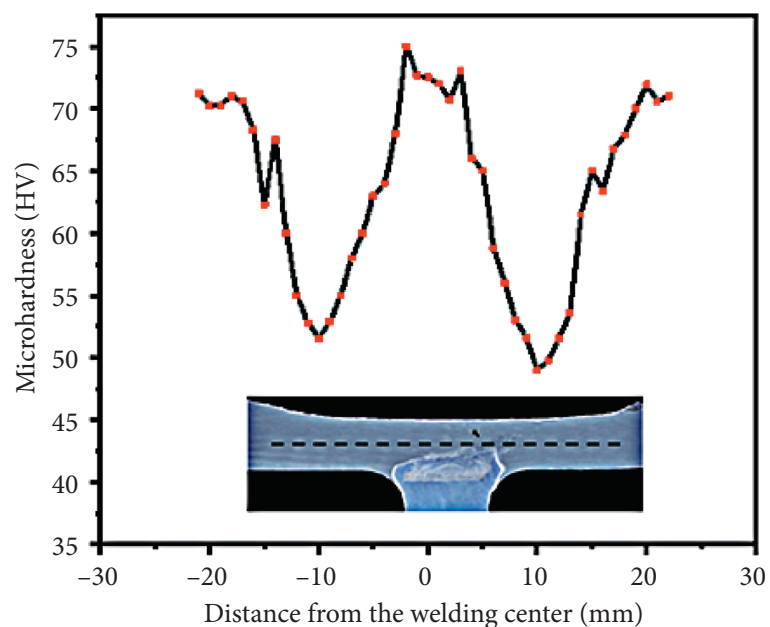

(a)

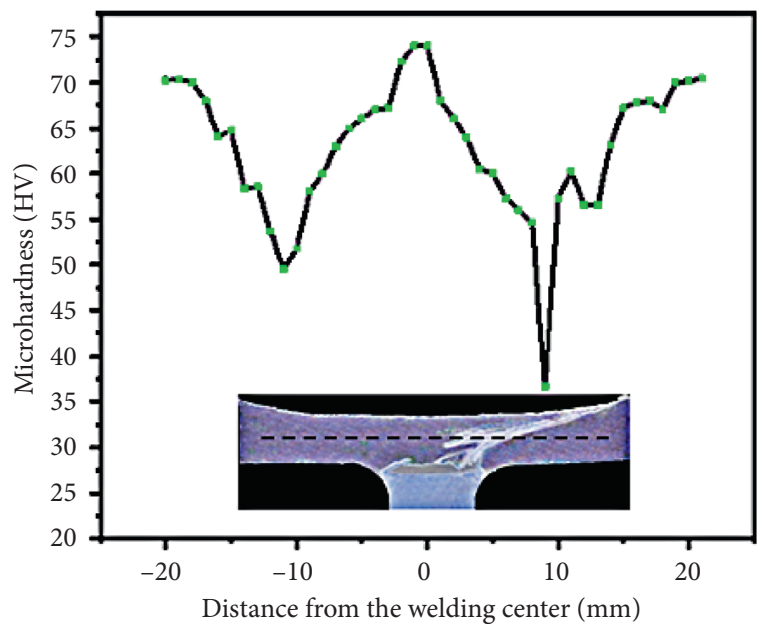

(b)

Figure 16: Continued. 


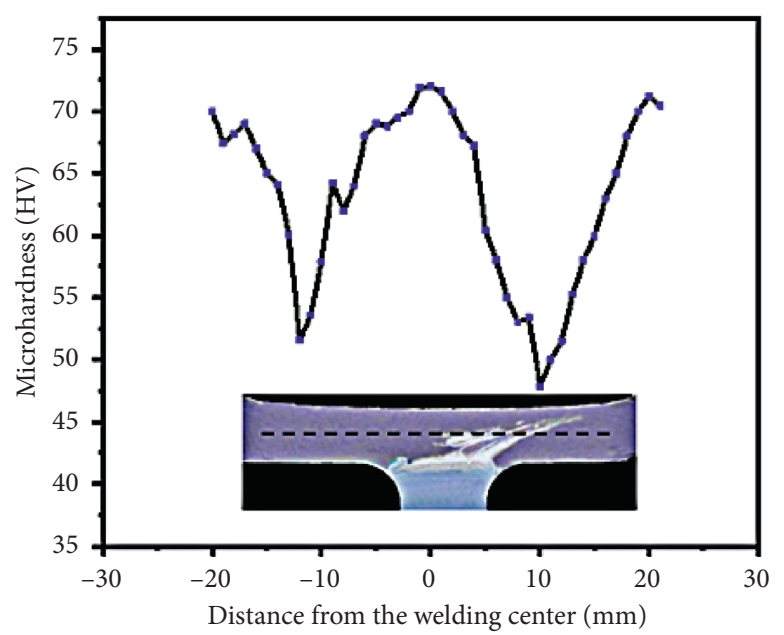

(c)

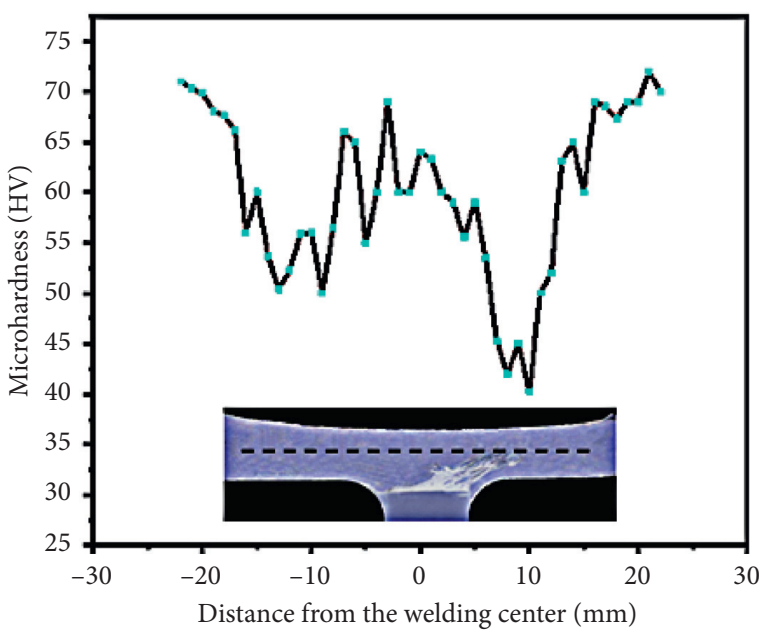

(d)

FIGURE 16: Sketch maps of microhardness tests on the skins with different traverse speeds: (a) $15 \mathrm{~mm} / \mathrm{min}$; (b) $30 \mathrm{~mm} / \mathrm{min}$; (c) $50 \mathrm{~mm} / \mathrm{min}$; (d) $65 \mathrm{~mm} / \mathrm{min}$.

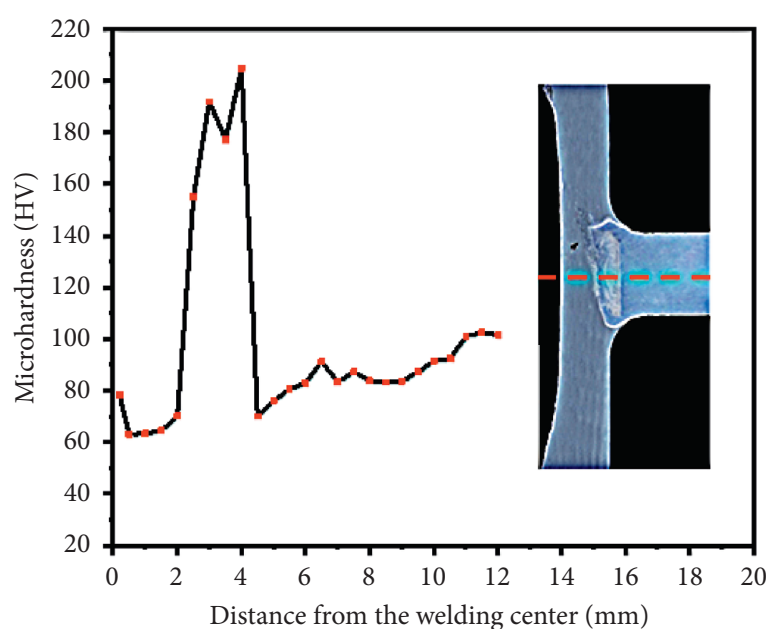

(a)

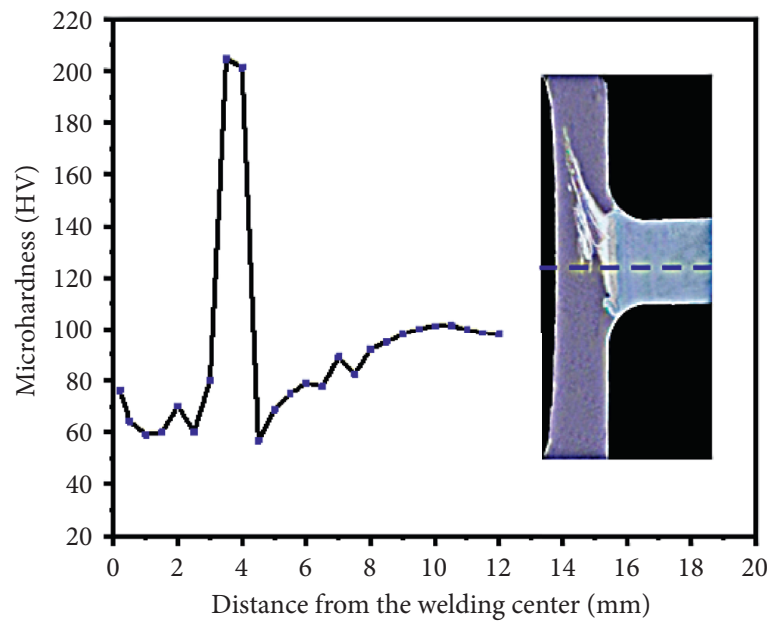

(c)

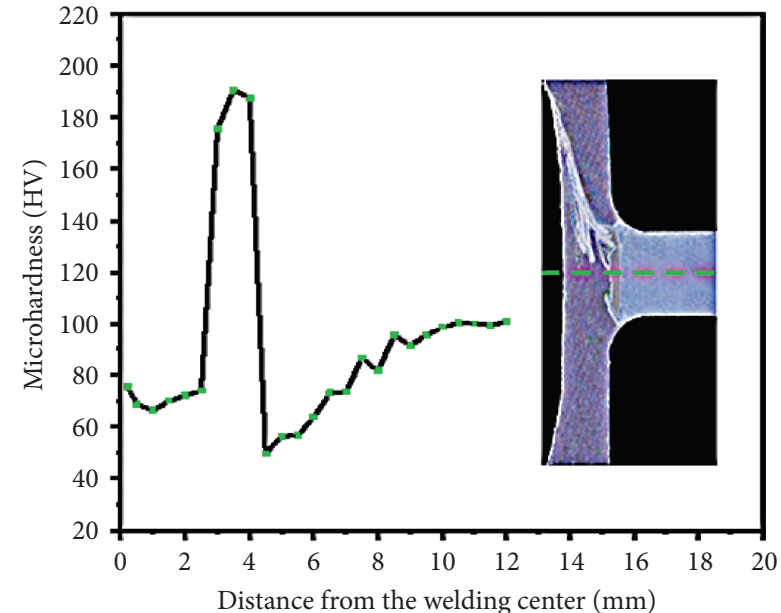

(b)

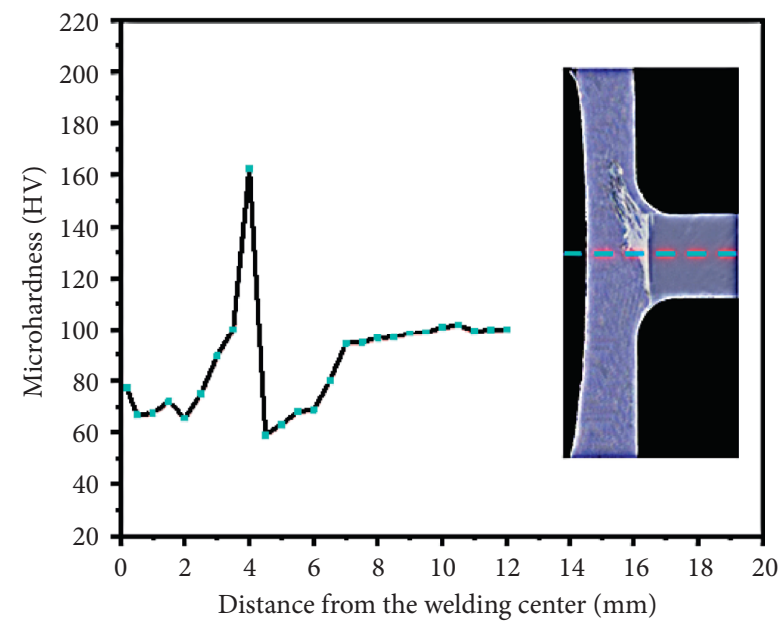

(d)

FIGURE 17: Sketch maps of microhardness tests on the stringers with different traverse speeds: (a) $15 \mathrm{~mm} / \mathrm{min}$; (b) $30 \mathrm{~mm} / \mathrm{min}$; (c) $50 \mathrm{~mm} /$ min; (d) $65 \mathrm{~mm} / \mathrm{min}$. 


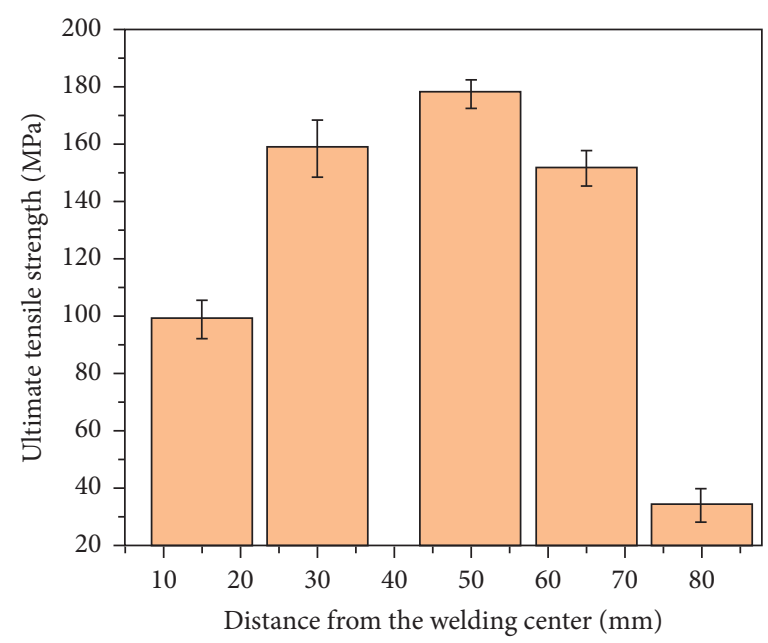

(a)

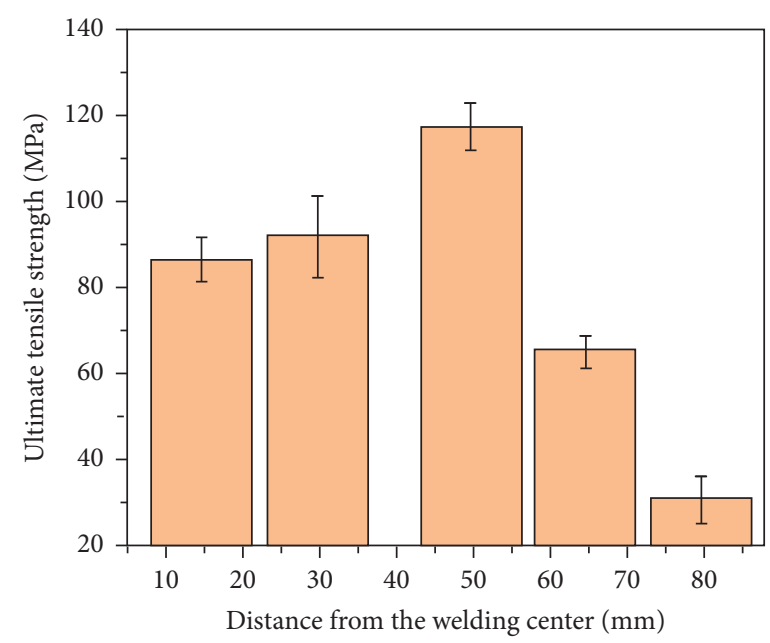

(b)

Figure 18: Tensile properties of all T-joints: (a) pulled along the skin and (b) pulled along the stringer.

shearing action of the pin and larger grain deformation occurred relative to the base material under the double action of the rotating force and the advancing force of the shoulder. On the RS, the material was not only squeezed and rubbed by the rotate tool but also squeezed by the metal in front of the rotating surface. Therefore, the distortion energy was increased and the work hardening effect is produced [24].

The four "N" type hardness profiles are shown in Figure 17. It can be found that the hardness values of the points close to the surface are higher than those of the NZ in the vertical direction of the skin because the top surface is in contact with air and the effect of aging strengthening is good with the temperature dropping rapidly. Then, within the range of about $2 \mathrm{~mm}$, the hardness values tend to be stable because the test points were in the SZ. The hardness value is very high in the range of about 2-4 mm. Obviously, the area is the $\mathrm{Mg}-\mathrm{Al} \mathrm{MRZ}$. Due to the formation of a fine equiaxed IMCs, the hardness value is very high and the highest hardness value reaches $204.5 \mathrm{HV}$ at $50 \mathrm{~mm} / \mathrm{min}$. The TMAZ is near the bottom of the MRZ, and the hardness value drops directly to the lowest. The TMAZ is located under the pin, so the shear force is small and it is too far away from the welding surface to sufficient heat input. All of these cannot lead to superplastic metal. After this, the hardness gradually increases to the level of the aluminum alloy BM [25].

It can be seen from Figure 18(a) that the ultimate tensile strength along the skin increases when the traverse speed is less than $50 \mathrm{~mm} / \mathrm{min}$. Nevertheless, the ultimate tensile strength of the joint decreases with increasing welding speed when the welding speed is greater than $50 \mathrm{~mm} / \mathrm{min}$. The sample has the highest ultimate tensile strength of $178.24 \mathrm{MPa}$ at $50 \mathrm{~mm} / \mathrm{min}$, equivalent to $91.9 \%$ of the BM. The ultimate tensile strength along the stringer has a similar change rule (as shown in Figure 18(b)). The highest ultimate tensile strength reaches $114 \mathrm{MPa}$, which is about $60 \%$ of the magnesium alloy base metal. It indicates that better metallurgical bonding occurs at the lap interface. When the traverse speed exceeds $50 \mathrm{~mm} / \mathrm{min}$, the tensile strength of the stringer decreases rapidly, because the increase prevents the $\mathrm{Al}$ and $\mathrm{Mg}$ elements from completely diffusing so that an effective metallurgical connection cannot be formed, resulting in a low tensile strength naturally.

Finally, the fracture features along the skin and stringer are analyzed, respectively. Figure 19 shows the SEM micrographs obtained from the fracture surface of the skin. There was too much heat input so that the failure surface is very flat and river patterns can be seen on the fractured surface of the welds fabricated by travel speeds (Figure 19(a)). This pattern, which is a feature of cleavage during fracture, is the main characteristic of brittle fracture due to the presence of a continuous intermetallic layer in the $\mathrm{Al} / \mathrm{Mg}$ interface and it may provide a brittle medium for crack propagation. There are many small cleavage surfaces and some ductile fracture marks on the fracture surface at $30 \mathrm{~mm} / \mathrm{min}$, which means that the fracture mode is a mixed fracture. In the FSW T-joints made using higher travel speed $(50 \mathrm{~mm} / \mathrm{min})$, necking is observed and the fracture surface revealed fine and deep dimples and a large number of micropores, indicating that excessive plastic deformation takes place during the tensile load test. Thus, the fracture mode is ductile. When the welding speed is up to $65 \mathrm{~mm} /$ 

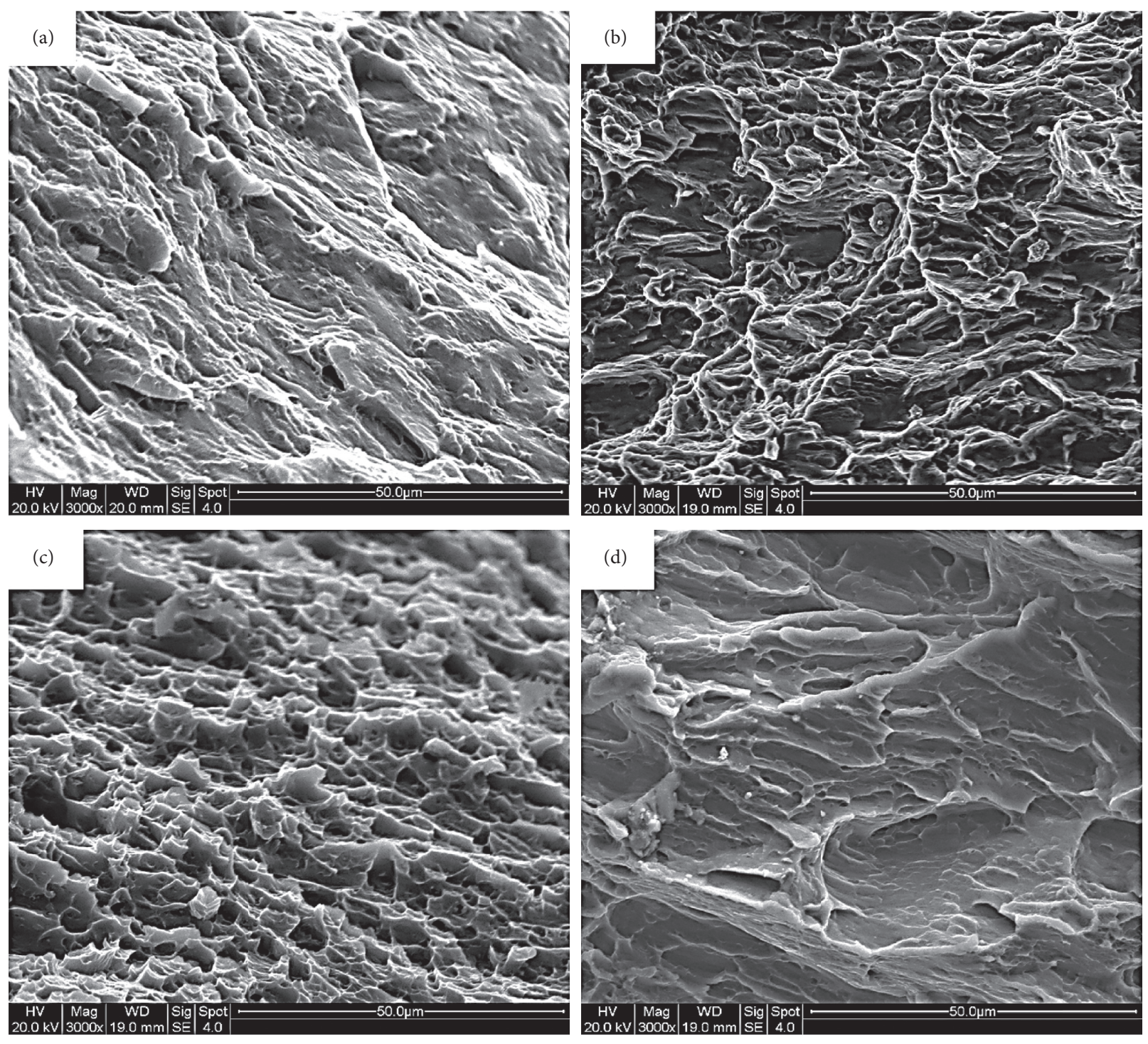

FIGURE 19: Fracture feature along the skins with different traverse speeds: (a) $15 \mathrm{~mm} / \mathrm{min}$; (b) $30 \mathrm{~mm} / \mathrm{min}$; (c) $50 \mathrm{~mm} / \mathrm{min}$; (d) $65 \mathrm{~mm} / \mathrm{min}$.

min, many cleavage surfaces and tear ridges suggest that the sample broke by brittle fracture [26]. Figure 20 shows the SEM micrographs obtained from the fracture surface of the stringer. Except for the welding speed of $50 \mathrm{~mm} / \mathrm{min}$, there are a lot of cleavage surfaces and river patterns on the fracture surfaces of all patterns, which is a typical ductile fracture. EDS results show that the crack is most likely initiated in the $\mathrm{Al}_{3} \mathrm{Mg}_{2}$ intermetallic compound layer, which exists at the bottom of MRZ and leads to the initiation of cracks [27]. Figure 19(c) shows that cleavage crack cores are generated at different locations and expand into cleavage facets. The quasicleavage fracture was indicated by the occurrence of many small cleavage surfaces and tearing edges on the fracture surface, coupled with several shallow dimples around them. 

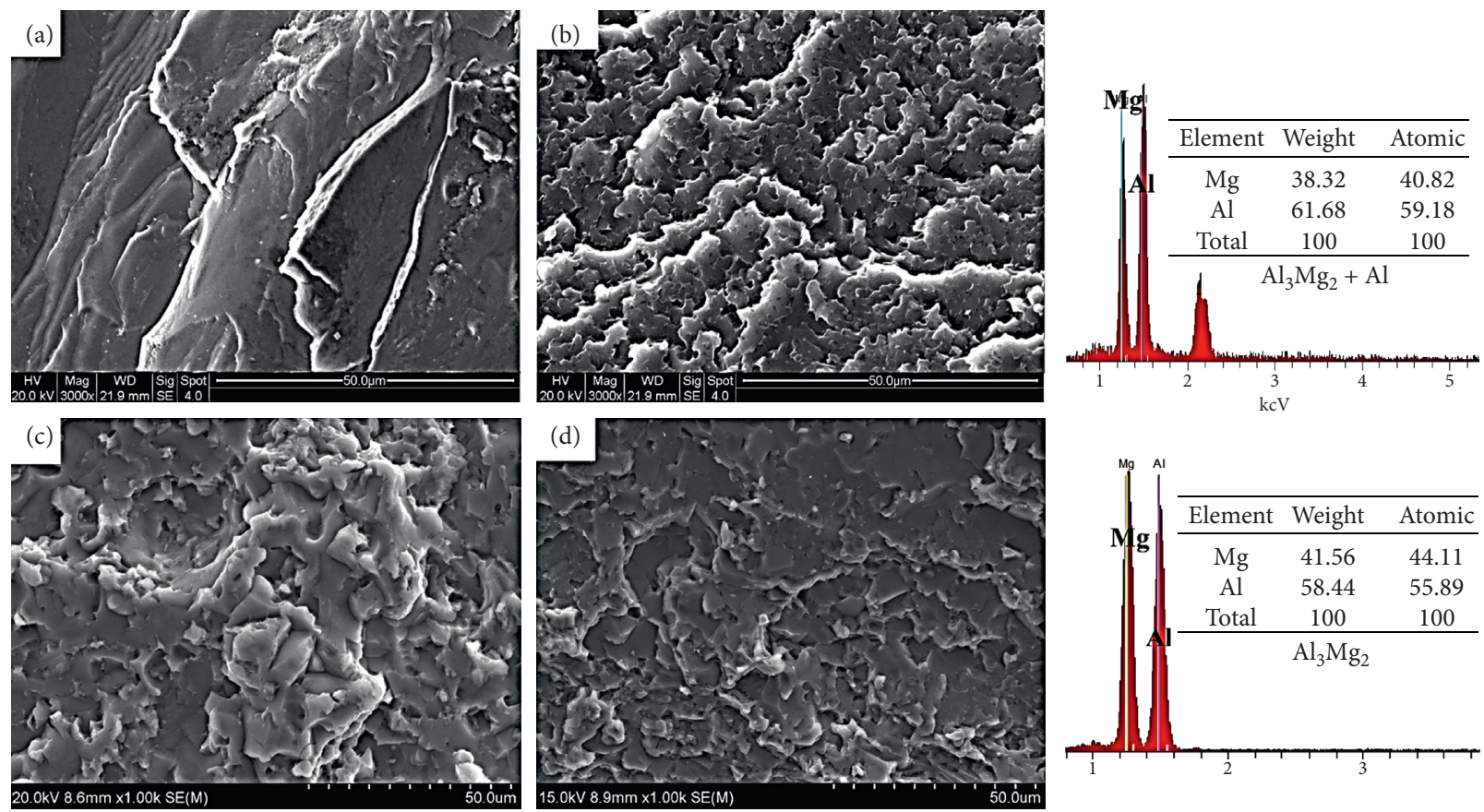

FIGURE 20: Fracture characteristics along the skins with different traverse speeds: (a) $15 \mathrm{~mm} / \mathrm{min}$; (b) $30 \mathrm{~mm} / \mathrm{min}$; (c) $50 \mathrm{~mm} / \mathrm{min}$; (d) $65 \mathrm{~mm} / \mathrm{min}$.

\section{Conclusion}

Through the study of the defect characteristics, metallurgical, structure, and mechanical properties of $\mathrm{Mg} / \mathrm{Al}$ T-joints, the following conclusions can be drawn:

(1) T-joints without tunnel defects can be obtained when the welding speed is $30-65 \mathrm{~mm} / \mathrm{min}$, and the weld formability is best when the welding speed is $50 \mathrm{~mm} / \mathrm{min}$.

(2) Cold lap and hook defects are found in all T-joints, which are connected to Mg-Al MRZ. The fillet welds of all T-joints were found to have kissing defects, and there were some oxides on the bonding line, which made cracks easier to produce.

(3) There are IMCs in the IS and LS. The network ES exists in the Mg-Al MRZ and the IMCs are finer and finer.

(4) All of the samples showed a similar microhardness profile in this experiment. The microhardness along the centerline of the skin showed a "W" distribution, the lowest hardness value appeared in $\mathrm{HAZ}$ on AS, and the microhardness of TMAZ on the RS was higher than that on the RS. The hardness profile along the centerline of the stringer is " $\mathrm{N}$ " type, the hardness near the lap interface is much higher than that of the base material, and the lowest hardness value appears on the TMAZ on the stringer.

(5) Kiss bonding defects are the main factors affecting tensile strength. The fracture mode along the skin is a ductile fracture and the fracture mode along the stringers is a quasicleavage fracture at $50 \mathrm{~mm} / \mathrm{min}$. The highest tensile strength along the skin, 178.24 MPa, reaches $91.9 \%$ of the BS; the highest tensile strength along the stringer is as high as $60 \%$ of the BS.

\section{Data Availability}

The data of this study will be used in subsequent studies, so they are not uploaded.

\section{Conflicts of Interest}

The authors declare that they have no conflicts of interest.

\section{Acknowledgments}

This study work was funded by the Graduate Innovation Base (Laboratory) Open Fund of Nanjing University of Aeronautics and Astronautics (no. kfjj20190607). This work was also supported by the College Students' Innovative Entrepreneurial Training Plan Program.

\section{References}

[1] G. Liu, L.-N. Ma, Z.-D. Ma et al., "Effects of welding speed and post-weld hot rolling on microstructure and mechanical properties of friction stir-welded AZ31 magnesium alloy," Acta Metallurgica Sinica-English Letters, vol. 31, no. 8, pp. 853-864, 2018.

[2] C. Wei, W. Wenxian, and L. Zepeng, "Microstructure evolution mechanism of $\mathrm{Al} / \mathrm{Mg}$ dissimilar joint during friction stir welding," Metallurgical Research and Technology, vol. 117, no. 3, 311 pages, 2020. 
[3] K. Sachin, W. Chuansong, and G. Song, "Process parametric dependency of axial downward force and macro- and microstructural morphologies in ultrasonically assisted friction stir welding of $\mathrm{Al} / \mathrm{Mg}$ alloys," Metallurgical and Materials Transactions A, vol. 51, pp. 2863-2881, 2020.

[4] F. Xiao-Song, L. Song-Bin, and T. Li-Na, "Refill friction stir spot welding of similar and dissimilar alloys: a review," Acta Metallurgica Sinica-English Letters, vol. 33, pp. 30-42, 2020.

[5] Z. Yadong, L. Yalong, and Z. Zhipen, "Fractal dimension characterization of joint surface morphology on dissimilar friction stir lap welding of Al/Mg," Materials, vol. 12, no. 23, p. 3941, 2019.

[6] S. Qi, R. Zhaoxu, and J. Shude, "Improving the mechanical property of dissimilar $\mathrm{Al} / \mathrm{Mg} \mathrm{Zn}$-added ultrasound-assisted friction stir lap welding joint by back propagation neural network-gray wolf optimization algorithm," Advanced Engineering Materials, vol. 21, 2019, https://www.researchgate. net/deref/http\%3A\%2F\%2Fdx.doi.org\%2F10.1002\%2Fadem. 201900973.

[7] L. Peng, F. Nie, H. Dong, S. Li, G. Yang, and H. Zhang, "Pulse MIG welding of 6061-T6/A356-T6 aluminum alloy dissimilar T-joint," Journal of Materials Engineering and Performance, vol. 27, pp. 4760-4769, 2018.

[8] F. Fomin, M. Fedor, V. Ventzke, P. Alvarez, S. Bauer, and N. Kashaev, "Metallurgical aspects of joining commercially pure titanium to Ti-6Al-4V alloy in a T-joint configuration by laser beam welding," The International Journal of Advanced Manufacturing Technology, vol. 97, no. 5-8, pp. 2019-2031, 2018.

[9] M. L. Saremi, S. E. Mirsalehi, and A. Shamsipur, "Investigation on metallurgical structure and mechanical properties of dissimilar Al 2024/Cu FSW T-joints," Transactions of the Indian Institute of Metals, vol. 70, pp. 1869-1877, 2017.

[10] M. D. Sameer and K. B. Anil, "Mechanical and metallurgical properties of friction stir welded dissimilar joints of AZ91 magnesium alloy and AA 6082-T6 aluminium alloy," Journal of Magnesium and Alloys, vol. 7, pp. 264-271, 2019.

[11] B. L. Prasad, G. Neelaiah, M. G. Krishna et al., "Joining of AZ91 Mg alloy and Al6063 alloy sheets by friction stir welding," Journal of Magnesium and Alloys, vol. 6, no. 1, pp. 71-76, 2018.

[12] M. Xiangchen, J. Yanye, J. Shude, and Y. Dejun, "Improving friction stir weldability of $\mathrm{Al} / \mathrm{Mg}$ alloys via ultrasonically diminishing pin adhesion," Journal Materials Science and Technology, vol. 34, no. 10, pp. 1817-1822, 2018.

[13] J. Mohammadi, Y. Behnamian, A. Mostafaei et al., "Friction stir welding joint of dissimilar materials between AZ31B magnesium and 6061 aluminum alloys: microstructure studies and mechanical characterizations," Materials Characterization, vol. 101, pp. 189-207, 2015.

[14] J. Shude, N. Shiyu, and L. Jianguang, "Dissimilar Al/Mg alloys friction stir lap welding with $\mathrm{Zn}$ foil assisted by ultrasonic," Journal Materials Science and Technology, vol. 35, no. 8, pp. 1712-1718, 2019.

[15] C. Lei and Y. Xinqi, "Characteristics of defects and tensile behaviors on friction stir welded AA6061-T4 T-joints," Materials Science and Engineering A, vol. 543, pp. 58-68, 2012, https:// www.sciencedirect.com/science/article/abs/pii/S09215093120025 11https://www.sciencedirect.com/science/article/abs/pii/S092150 9312002511https://www.sciencedirect.com/science/article/abs/pi i/S0921509312002511.

[16] Z. Yong and Y. Xinqi, "Defects and tensile properties of 6013 aluminum alloy T-joints by friction stir welding," Materials and Design, vol. 57, pp. 146-155, 2014.
[17] E. E. Feistauer, L. A. Bergmann, and J. F. dos Santos, "Effect of reverse material flow on the microstructure and performance of friction stir welded T-joints of an Al-Mg alloy," Materials Science and Engineering: A, vol. 731, pp. 454-464, 2018.

[18] L. Fratini, G. Buffaa, and R. Shivpuri, "Influence of material characteristics on plastomechanics of the FSW process for T-joints," Materials and Design, vol. 30, no. 7, pp. 2435-2445, 2009.

[19] L. Fratini, G. Buffa, L. Filice, and F. Gagliardi, "Friction stir welding of AA6082-T6 T-joints: process engineering and performance measurement," Proceedings of the Institution of Mechanical Engineers, Part B: Journal of Engineering Manufacture, vol. 220, no. 5, pp. 669-676, 2006.

[20] Y. Yinfei, S. Yifu, and G. Chao, "Friction plug welding acrylonitrile butadiene styrene sheets: the investigation of welding process, joint morphology and mechanical property," International Journal of Material Forming, vol. 12, pp. 845855, 2018, https://www.researchgate.net/deref/http\%3A\%2F\% 2Fdx.doi.org\%2F10.1007\%2Fs12289-018-1456-x.

[21] L. Wenming, Y. Yinfei, S. Tao, and W. Siyu, "Influence of cooling water temperature on ME20M magnesium alloy submerged friction stir welding: a numerical and experimental study," International Journal of Advanced Manufacture Technology, vol. 105, no. 3, pp. 5203-5215, 2019, https:// www.researchgate.net/deref/https\%3A\%2F\%2Flink.springer. com\%2Farticle\%2F10.1007\%252Fs00170-019-04496-2.

[22] C. Rajendran, K. Srinivasan, and V. Balasubramanian, "Identifying combination of friction stir welding parameters to maximize strength of lap joints of AA2014-T6 aluminium alloy," Archives of Mechanical Technology and Materials, vol. 37, no. 1, pp. 6-21, 2017, https://www.researchgate.net/ deref/http\%3A\%2F\%2Fdx.doi.org\%2F10.1515\%2Famtm2017-0002.

[23] H. Tengfei, X. Meng, Z. Ying, and S. Yifu, "Laser cladding NiTi-Cr alloy coatings with different process parameters," Materials and Manufacturing Processes, vol. 34, pp. 17101718, 2019, https://www.researchgate.net/deref/http\%3A\%2F \%2Fdx.doi.org\%2F10.1080\%2F10426914.2019.1686521.

[24] C. Rajendran, K. Srinivasan, V. Balasubramanian, H. Balaji, and P. Selvaraj, "Effect of tool tilt angle on strength and microstructural characteristics of friction stir welded lap joints of AA2014-T6 aluminum alloy," Transactions of Nonferrous Metals Society of China, vol. 29, no. 9, pp. 1824-1835, 2019.

[25] Y. S. Sato, S. H. C. Park, M. Michiuchi, and H. Kokawa, "Constitutional liquation during dissimilar friction stir welding of $\mathrm{Al}$ and Mg alloys," Scripta Materialia, vol. 50, no. 9, pp. 1233-1236, 2004.

[26] A. Astarita, A. Squillace, A. Scala, and A. Prisco, "On the critical technological issues of friction stir welding T-joints of dissimilar aluminum alloys," Journal of Materials Engineering and Performance, vol. 21, no. 8, pp. 1763-1771, 2012.

[27] C. Rajendran, K. Srinivasan, and V. Balasubramanian, "Evaluation of load-carrying capabilities of friction stir welded, TIG welded and riveted joints of AA2014-T6 aluminium alloy," Aircraft Engineering and Aerospace Technology, vol. 91, pp. 1238-1244, 2019, https://www.researchgate.net/deref/http \%3A\%2F\%2Fdx.doi.org\%2F10.1108\%2FAEAT-11-20170233. 